\title{
Amelioration of oxidative stress, inflammation and liver function by nutraceuticals in rat model of hepatic cancer initiation induced by $\mathrm{N}$-nitrosodiethylamine
}

\author{
Sahar Y. Al-Okbi ${ }^{(\mathbb{D}}$, Doha A. Mohamed $^{\mathbb{D}}$, Hagar F.H. Elbakry ${ }^{\mathbb{D}}$ \\ Nutrition and Food Sciences Department, National Research Centre, Cairo, Egypt
}

\section{A R T I C L E IN F O}

Article Type:

Original Article

\section{Article History:}

Received: 15 August 2020

Accepted: 4 November 2020

\section{Keywords:}

Cancer initiation

$\mathrm{N}$-nitrosodiethylamine

Plants extracts

Inflammation

Oxidative stress

Liver function

\begin{abstract}
A B S T R A C T
Introduction: Nutraceuticals might serve as protective agent against liver cancer induced by pro-cancerous chemicals that initiate high oxidative stress, inflammation and affect DNA integrity. The aim of the present research was to study the prevention of hepatocellular carcinoma initiation induced by $\mathrm{N}$-nitrosodiethylamine (NDEA) through treatment by nutraceuticals.

Methods: Two nutraceuticals were prepared; the first (NI) was a mixture of different extracts of green tea, wheat germ and tomato, the second one (NII) was composed of extracts mixture of broccoli, hazelnuts and carrot. Total flavonoids and flavonols were determined in the nutraceuticals. Four groups of rats were run; the first served as control normal, the other three groups were treated by intraperitoneal injection of NDEA, one of these groups was designated as control NDEA, the other two groups (test groups) were treated daily with oral doses of NI and NII, respectively. The experiment continued for 8 weeks. Plasma transaminases, alkaline phosphatase and catalase activities, total protein, albumin, malondialdehyde (MDA) and tumor necrosis factor- $\alpha$ (TNF- $\alpha$ ) along with liver MDA level and catalase activity were assessed.

Results: NI showed higher flavonoids and lower flavonols than NII $(P<0.05)$. High oxidative stress and inflammation biomarkers, liver dysfunction, reduced plasma albumin and total protein were demonstrated in control NDEA compared to control normal $(P<0.05)$. Test groups showed significant improvement in all parameters $(P<0.05)$ compared to NDEA control. NI was superior in improving plasma transaminases and catalase activities, MDA and TNF- $\alpha$ levels and liver catalase activity compared to NII $(P<0.05)$.

Conclusion: Both NI and NII might prevent liver cancer initiation during exposure to carcinogenic agents, NI being superior to NII.
\end{abstract}

Implication for health policy/practice/research/medical education:

This research showed that extract mixtures of green tea, wheat germ and tomato (NI), and broccoli, hazelnuts and carrot (NII) prevent liver cancer initiation induced by NDEA; the mechanism probably involves antioxidant and anti-inflammatory activities beside improvement of liver function. These nutraceuticals might be also used as chemotherapeutic adjunct for management of liver cancer.

Please cite this paper as: Al-Okbi SY, Mohamed DA, Elbakry HFH. Amelioration of oxidative stress, inflammation and liver function by nutraceuticals in rat model of hepatic cancer initiation induced by N-nitrosodiethylamine. J Herbmed Pharmacol. 2021;10(2):194-201. doi: 10.34172/jhp.2021.21.

\section{Introduction}

$\mathrm{N}$-nitrosamine contaminated food is considered as a risk factor for developing hepatocellular carcinoma (1). $\mathrm{N}$-nitrosamine is produced from the reaction between nitrosating agent that derived from nitrite or smoke and a secondary amine originated from protein and lipid degradation during processing of meat products (2).
Diethyl nitrosamine, an $\mathrm{N}$-nitrosamine compound, is used to induce initiation of hepatocellular carcinoma in animals (3). N-nitrosodiethylamine (NDEA) is an organic compound which is present in tobacco smoking and possesses carcinogenic and mutagenic effects. It is used as additive in gasoline and lubricant industries. It affects DNA integrity through alkylation and is considered as 
human liver carcinogen, so it is used in research to induce liver tumorigenesis and several nuclear aberrations in the rat liver to search new anticancer agents $(4,5)$. NDEA produces reactive oxygen species leading to high oxidative stress and hepatocellular damage involved in the pathogenesis of hepatocellular carcinoma (3).

The prevalence of cancer nowadays might be related to continual exposure to carcinogenic agents, high oxidative stress and chronic inflammation in addition to genetic predisposition. Hepatocellular carcinoma was reported as the third cancer related mortality worldwide $(6,7)$. Though the thorough pathogenesis of hepatocellular carcinoma is not fully investigated; oxidative stress, inflammation and lesions caused by chemical carcinogens are involved (8). It is well accepted that reactive oxygen species accumulation is one of the important factors in motivating malignancy progression (9). Liver cancer is considered as one of the most resistant cancers to chemotherapeutic agents and so far there is no efficient regimen for treating hepatocellular carcinoma (10). Consequently the concept of prevention of such rigorous cancer must be developed specially during unavoidable exposure to carcinogens within such industrialized world.

Naturally occurring bioactive constituents specially those obtained from botanical dietary sources namely nutraceuticals are recently considered as safe agents for protection from carcinogenesis. Nutraceuticals are defined differently by different nutritional societies; however it is the best to be defined as bioactive constituents prepared from food sources that elucidate protection or treatment of one or more chronic diseases. Nutraceuticals might prevent cancer when contain bioactive phytonutrients and phytochemicals that possess antioxidant and antiinflammatory activities. Such bioactive components like carotenoids, flavonoids, tocopherols and phytosterols might fulfill the aforementioned properties. Carrots, tomatoes, broccoli, green tea, hazelnuts and wheat germ are reported as rich sources of antioxidant and anti-inflammatory bioactive constituents $(11,12)$. In previous studies belonged to the present research team; nutraceuticals prepared from a mixture of ethanol extract of green tea, wheat germ oil and acetone extract of tomato and another mixture of ethanol extract of broccoli, hazelnuts oil and acetone extract of carrot were shown to possess anti-inflammatory effect in adjuvant arthritis as well as in vitro antioxidant activity and inhibiting effect on cell line liver carcinoma (HEPG2) $(13,14)$. So, it is of interest to investigate the in-vivo protective effect of such nutraceuticals towards initiation of malignancy during exposure to carcinogenic agent.

The objective of the present research was to study the protective role of the aforementioned nutraceuticals against liver cancer in rats treated by NDEA as procarcinogenic agent. This was accomplished through following up antioxidant, oxidative stress, inflammatory biomarkers and liver function in such rats. The aim also included assessment of total flavonoids and flavonols of the nutraceuticals.

\section{Materials and Methods}

Plant materials

Fresh tomato, carrot, broccoli, green tea and hazelnuts were purchased from local markets, while wheat germ was obtained from South Cairo Milling Co., Egypt.

\section{Chemicals}

$\mathrm{N}$-nitrosodiethylamine was purchased from Sigma (St. Louis, MO, USA). All other chemicals were of the highest grade.

\section{Animals}

Male Sprague Dawley rats weighing 150-170 g. were used in the present study. Animals were obtained from Animal House of National Research Centre, Cairo, Egypt. Animals were kept individually in stainless steel cages; water and food were given ad-labium with $12 \mathrm{~h}$ dark/light cycle.

\section{Diets}

A balanced diet composed of $10 \%$ casein, $10 \%$ corn oil, $23.5 \%$ sucrose, $47 \%$ maize starch, $5 \%$ cellulose, $3.5 \%$ salt mixture and $1 \%$ vitamin mixture was prepared for feeding rats all over the experimental period.

Preparation of plant materials

Fresh tomato, carrot and broccoli were washed by tap water and cut into small pieces. All plants' materials were dried separately in hot air oven at $40^{\circ} \mathrm{C}$ and reduced into coarse powder.

\section{Preparation of plant extracts}

Plant extractions were carried out as reported previously (13). The dried powder of tomato and carrot were placed separately in a continuous extraction apparatus (soxhlet) and subjected to extraction using acetone for extraction of carotenoids including lycopenes. Hazelnuts and wheat germ were extracted separately by soxhlet apparatus using petroleum ether $\left(40-60^{\circ} \mathrm{C}\right)$ for preparation of the oil. Green tea and broccoli were placed separately in a continuous extraction apparatus and subjected to crude extraction using ethanol. The solvent of each extract was completely removed by evaporation under reduced pressure at a temperature not exceeding $40^{\circ} \mathrm{C}$.

Preparation of nutraceuticals (extracts' mixtures)

Equal weights from crude ethanol extract of green tea, wheat germ oil and acetone extract of tomato were mixed to give nutraceutical I (NI). Nutraceutical II (NII) was prepared from crude ethanol extract of broccoli, hazelnuts oil and acetone extract of carrot as 1:1:1 (w/w/w). The nutraceuticals were prepared as described previously (13). 
Preparation of nutraceuticals' dosages

Nutraceuticals were prepared in emulsion form using water and gum acacia as emulsifying agent. A vehicle was prepared containing the same amount of water and gum acacia for dosing the rats of the control groups.

Determination of flavonoids content in the mixtures Total flavonoids were determined in the nutraceuticals as reported previously (15). Aluminum chloride ( $\mathrm{AlCl} 3$ ) was prepared in ethanol as $20 \mathrm{~g} / \mathrm{L}$. AlCl3 solution (0.5 $\mathrm{mL}$ ) was added to $0.5 \mathrm{ml}$ of the nutraceuticals. After 1 $\mathrm{h}$ of incubation at room temperature, the absorbance of samples was measured at (420) $\mathrm{nm}$. The development of yellow color was an indicator of the presence of flavonoids. Quercetin was used as standard. Total flavonoids content was expressed as $\mathrm{mg}$ quercetin equivalent $(\mathrm{QE}) / \mathrm{g}$ nutraceutical.

Determination of flavonols content in the mixtures

Total flavonols were determined in the nutraceuticals as described previously (16). $\mathrm{AlCl} 3$ was prepared in methanol as $2 \mathrm{~g} / 100 \mathrm{~mL}$. AlCl3 solution $(1 \mathrm{~mL})$ was added to $1 \mathrm{ml}$ of the nutraceuticals, followed by $3 \mathrm{ml}$ sodium acetate solution (5\%). The reaction mixture was left 2.5 hours at room temperature. The absorbance was read at $440 \mathrm{~nm}$. Total flavonols content was expressed as $\mu \mathrm{g}$ quercetin equivalent $(\mathrm{QE}) / \mathrm{g}$ nutraceutical.

\section{Experimental design}

Thirty-two male rats were divided into four groups each of eight rats. Rats of group 1 served as normal control. Group 2 was NDEA control group. Rats of group 3 and 4 were given daily oral doses of NI and NII emulsions (300 $\mathrm{mg}$ nutraceutical $/ \mathrm{kg}$ rat body weight), respectively for eight weeks. The rats in groups 2, 3 and 4 were treated by intraperitoneal injection of NDEA $(200 \mathrm{mg} / \mathrm{kg}$ rat body weight) dissolved in saline to initiate the process of hepatocarcinogenesis according to the previous protocol of Srivastava et al (17). The rats of group one received an intraperitoneal injection of saline and the rats of group 1 and 2 were treated by daily oral doses of the vehicle for eight weeks. During the experiment, body weight and food intake were recorded weekly. After eight weeks (end of the study) total food intake, body weight gain and food efficiency ratio (body weight gain/total food intake) were calculated. Blood samples were collected in heparinized test tubes from the anaesthetized rats after an overnight fast. Plasma samples were separated by centrifugation at $3000 \mathrm{rpm}$ for 15 minutes. Plasma alanine aminotransferase (ALT), aspartate aminotransferase (AST) and alkaline phosphatase (ALP) activities were assessed as liver function indicators by colorimetric techniques $(18,19)$. Plasma total protein and plasma albumin (A) were determined by colorimetric methods $(20,21)$ as extra indicators of liver function. Plasma globulin $(G)$ and
A/G ratio were calculated. Plasma malondialdehyde (MDA), as indicator of lipid peroxidation, plasma catalase activity, an antioxidant biomarker, and plasma tumor necrosis factor- $\alpha$ (TNF- $\alpha$ ), as inflammatory marker, were estimated (22-24). After blood sampling, rats were immediately sacrificed and the liver was separated from each animal, weighed and analyzed for MDA level and catalase activity $(22,23)$. Percentage liver weight/body weight was calculated for each rat.

\section{Statistical analysis}

Results of animal experiment were expressed as mean \pm SE. Different groups were compared statistically using One Way Analysis of Variance (ANOVA) followed by LSD test, SPSS, version 22. $T$ test was applied for comparing total flavonoids and flavonols in the nutraceuticals. In both tests the means were considered significantly different at $P \leq 0.05$.

\section{Results}

Flavonoids and flavonols contents of the studied nutraceuticals are demonstrated in Table $1 . \mathrm{N} 1$ contained higher flavonoids and lower flavonols $(2 \pm 0.04 \mathrm{mg} \mathrm{QE} / \mathrm{g}$ and $1.58 \pm 0.03 \mu \mathrm{g} Q \mathrm{QE} / \mathrm{g}$, respectively) than NII ( $0.7 \pm$ $0.01 \mathrm{QE} / \mathrm{g}$ and $18.46 \pm 0.91 \mu \mathrm{g} \mathrm{QE} / \mathrm{g}$, respectively) where $(P<0.05)$.

Nutritional parameters and percentage of liver weight/body weight of different experimental groups are compiled in Table 2. The control group treated with NDEA showed significant reduction of body weight gain, final body weight, total food intake and food efficiency ratio with increase in percentage of liver weight/body weight compared to normal control group. All nutritional parameters of the test groups (groups treated with the nutraceuticals) demonstrated significant increase compared to NDEA control; while still significantly lower than the normal control. No significant change was demonstrated between the two test groups, however; the group treated with NI showed significant reduction of percentage of liver weight/body weight compared to NDEA control, while that of NII did not demonstrate any significant change.

Liver function tests (plasma ALT, AST and ALP activities) demonstrated significant elevation in NDEA control compared to normal control (Table 3). Treatment with NI and NII produced significant reduction of plasma ALT, AST and ALP activities compared to NDEA control;

Table 1. Flavonoids and flavonols contents of nutraceuticals

\begin{tabular}{lcc}
\hline & Nutraceutical I & Nutraceutical II \\
\hline Flavonoids (mg QE/g nutraceutical) & $2 \pm 0.04$ & $0.7 \pm 0.01^{*}$ \\
Flavonols ( $\mu \mathrm{g}$ QE/g nutraceutical) & $1.58 \pm 0.03$ & $18.46 \pm 0.91^{*}$ \\
\hline
\end{tabular}

QE: Quercetin equivalent.

* Significant change at $P<0.05$. 
Table 2. Nutritional parameters of different experimental groups

\begin{tabular}{llllll}
\hline Groups & $\begin{array}{l}\text { Initial body } \\
\text { weight }\end{array}$ & Final body weight & Body weight gain & Total food intake & $\begin{array}{l}\text { Food efficiency ratio } \\
\% \text { of liver weight/ } \\
\text { body weight }\end{array}$ \\
\hline Normal control & $164.75^{\mathrm{a}} \pm 1.37$ & $262.25^{\mathrm{a}} \pm 1.50$ & $97.50^{\mathrm{a}} \pm 1.35$ & $786.00^{\mathrm{a}} \pm 7.73$ & $0.12^{\mathrm{a}} \pm 0.0015$ \\
NDEA control & $164.75^{\mathrm{a}} \pm 1.32$ & $202.88^{\mathrm{b}} \pm 1.89$ & $38.13^{\mathrm{b}} \pm 1.08$ & $464.38^{\mathrm{b}} \pm 7.64$ & $0.08^{\mathrm{b}} \pm 0.0024$ \\
NDEA\& NI & $164.75^{\mathrm{a}} \pm 1.25$ & $214.25^{\mathrm{c}} \pm 1.93$ & $49.50^{\mathrm{c}} \pm 0.93$ & $494.88^{\mathrm{c}} \pm 5.23$ & $0.10^{\mathrm{c}} \pm 0.0015$ \\
NDEA\& NII & $164.63^{\mathrm{a}} \pm 1.13$ & $212.75^{\mathrm{c}} \pm 1.60$ & $48.13^{\mathrm{c}} \pm 1.97$ & $494.88^{\mathrm{c}} \pm 4.56$ & $0.10^{\mathrm{c}} \pm 0.0038$ \\
\hline
\end{tabular}

NDEA control: Control group treated by N-nitrosodiethylamine, NDEA\& N I: Group treated by N-nitrosodiethylamine and nutraceutical I, NDEA \& N II: Group treated by N-nitrosodiethylamine and nutraceutical II.

Values are means $\pm \mathrm{SE}$; where $\mathrm{n}=8$. In the same column; the similar superscript letters mean insignificant difference while the different superscript letters mean significant different at $P \leq 0.05$.

Table 3. Liver function tests of different experimental groups

\begin{tabular}{lccc}
\hline Groups & Plasma ALT activity (IU/L) & Plasma AST activity (IU/L) & Plasma ALP activity (IU/L) \\
\hline Normal control & $39.63^{\mathrm{a}} \pm 0.73$ & $52.25^{\mathrm{a}} \pm 0.62$ & $160.25^{\mathrm{a}} \pm 2.19$ \\
NDEA control & $72.50^{\mathrm{b}} \pm 1.20$ & $87.75^{\mathrm{b}} \pm 1.31$ & $205.25^{\mathrm{b}} \pm 4.62$ \\
NDEA \& N I & $51.75^{\mathrm{c}} \pm 0.88$ & $68.13^{\mathrm{c}} \pm 1.13$ & $167.63^{\mathrm{ac}} \pm 1.25$ \\
NDEA \& N II & $59.75^{\mathrm{d}} \pm 0.84$ & $72.00^{\mathrm{d}} \pm 0.76$ & $168.88^{\mathrm{c}} \pm 1.82$
\end{tabular}

AST, aspartate transaminase; ALT: alanine Transaminases, ALP: Alkaline phosphatase, NDEA control: Control group treated by N-nitrosodiethylamine, NDEA \& N I: Group treated by N-nitrosodiethylamine and nutraceutical I, NDEA \& N II: Group treated by N-nitrosodiethylamine and nutraceutical II.

Values are means $\pm \mathrm{SE}$; where $\mathrm{n}=8$. In the same column; the similar superscript letters mean insignificant difference while the different superscript letters mean significant different at $P \leq 0.05$.

but ALP activity of the group given NI matched that of the normal control.

Plasma total protein and albumin were significantly reduced in NDEA control compared to normal control. The groups treated with NI and NII showed significant elevation of plasma total protein and albumin compared to NDEA control, where the levels were normalized except for total protein in case of NI group. Plasma globulin and $\mathrm{A} / \mathrm{G}$ ratio though showed reduction in control NDEA compared to control normal however the reductions were not significant. The test groups showed minor elevation in both plasma globulin and A/G ratio compared to NDEA control which was only significant in case of $A / G$ ratio of rats treated with NI (Table 4).

Table 5 shows significant elevation of plasma MDA and TNF- $\alpha$ with significant reduction of plasma catalase activity in NDEA control group compared to normal control. Significant elevation of plasma catalase activity with significant reduction of plasma MDA and TNF- $\alpha$ were observed on treatment of either nutraceuticals while NI demonstrated significant improvement compared to NII; the levels still not matching the normal control group. In NDEA control; liver MDA, was significantly higher while catalase activity was significantly lower than control normal (Table 6). These changes were significantly improved on treatment with either NI or NII. Liver catalase activity in case of NI was significantly higher than that of NII. Liver MDA and catalase were still significantly different from that of normal control.

\section{Discussion}

Exposures to high oxidative stress and continual inflammatory state are among the main factors that could lead to cancer especially with the presence of genetic factors. High oxidative stress might prim oxidation of DNA and mutation which is a pre-cancerous stage.

Table 4. Plasma protein levels of different experimental groups

\begin{tabular}{llccc}
\hline Groups & Total protein $(\mathrm{mg} / \mathrm{dL})$ & Albumin $(\mathrm{mg} / \mathrm{dL})$ & Globulin $(\mathrm{mg} / \mathrm{dL})$ & Albumin/globulin \\
\hline Normal control & $6.43^{\mathrm{a}} \pm 0.06$ & $3.38^{\mathrm{a}} \pm 0.05$ & $3.04^{\mathrm{a}} \pm 0.05$ & $1.11^{\mathrm{ab}} \pm 0.03$ \\
NDEA control & $5.78^{\mathrm{b}} \pm 0.09$ & $2.84^{\mathrm{b}} \pm 0.07$ & $2.94^{\mathrm{a}} \pm 0.11$ & $0.98^{\mathrm{b}} \pm 0.05$ \\
NDEA \& N I & $6.09^{\mathrm{c}} \pm 0.06$ & $3.24^{\mathrm{a}} \pm 0.08$ & $2.85^{\mathrm{a}} \pm 0.12$ & $1.16^{\mathrm{a}} \pm 0.07$ \\
NDEA \& N II & $6.32^{\mathrm{a}} \pm 0.09$ & $3.31^{\mathrm{a}} \pm 0.04$ & $3.01^{\mathrm{a}} \pm 0.11$ & $1.11^{\mathrm{ab}} \pm 0.05$ \\
\hline
\end{tabular}

NDEA control: Control group treated by N-nitrosodiethylamine, NDEA \& N I: Group treated by N-nitrosodiethylamine and nutraceutical I, NDEA \& N II: Group treated by N-nitrosodiethylamine and nutraceutical II.

Values are means $\pm \mathrm{SE}$; where $\mathrm{n}=8$. In the same column; the similar superscript letters mean insignificant difference while the different superscript letters mean significant different at $P \leq 0.05$. 
Table 5. Plasma antioxidant and anti-inflammatory biomarkers of different experimental groups

\begin{tabular}{llll}
\hline Groups & MDA $(\mathrm{nmol} / \mathrm{mL})$ & Catalase activity $(\mathrm{u} / \mathrm{L})$ & $\mathrm{TNF}-\boldsymbol{\alpha}(\mathrm{pg} / \mathrm{mL})$ \\
\hline Normal control & $7.06^{\mathrm{a}} \pm 0.15$ & $469.38^{\mathrm{a}} \pm 3.95$ & $19.90^{\mathrm{a}} \pm 0.51$ \\
NDEA control & $23.13^{\mathrm{b}} \pm 0.69$ & $211.04^{\mathrm{b}} \pm 5.21$ & $39.38^{\mathrm{b}} \pm 1.00$ \\
NDEA \& N I & $13.79^{\mathrm{c}} \pm 0.26$ & $426.68^{\mathrm{c}} \pm 4.68$ & $26.25^{\mathrm{c}} \pm 0.53$ \\
NDEA \& N II & $15.19^{\mathrm{d}} \pm 0.35$ & $378.50^{\mathrm{d}} \pm 5.76$ & $30.13^{\mathrm{d}} \pm 0.74$ \\
\hline
\end{tabular}

MDA: Malondialdehyde, TNF- $\alpha$ : Tumor necrosis factor-alpha, NDEA control: Control group treated by N-nitrosodiethylamine, NDEA\& N I: Group treated by N-nitrosodiethylamine and nutraceutical I, NDEA \& N II: Group treated by N-nitrosodiethylamine and nutraceutical II.

Values are means $\pm S E$; where $n=8$. In the same column; the similar superscript letters mean insignificant difference while the different superscript letters mean significant different at $P \leq 0.05$.

Table 6. Liver catalase and MDA of different experimental groups

\begin{tabular}{lcc}
\hline Groups & $\begin{array}{c}\text { Liver catalase activity } \\
(\mathrm{u} / \mathrm{L})\end{array}$ & $\begin{array}{c}\text { Liver MDA } \\
(\mathrm{nmol} / \mathrm{mL})\end{array}$ \\
\hline Normal control & $363.75^{\mathrm{a}} \pm 5.83$ & $10.31^{\mathrm{a}} \pm 0.38$ \\
NDEA control & $228.12^{\mathrm{b}} \pm 3.55$ & $17.48^{\mathrm{b}} \pm 0.50$ \\
NDEA \& N I & $316.56^{\mathrm{c}} \pm 4.74$ & $12.81^{\mathrm{c}} \pm 0.39$ \\
NDEA \& N II & $266.07^{\mathrm{d}} \pm 7.52$ & $13.40^{\mathrm{c}} \pm 0.34$ \\
\hline
\end{tabular}

MDA: Malondialdehyde, NDEA control: Control group treated by $\mathrm{N}$-nitrosodiethylamine, NDEA \& $\mathrm{N}$ I: Group treated by N-nitrosodiethylamine and nutraceutical I, NDEA \& N II: Group treated by $\mathrm{N}$-nitrosodiethylamine and nutraceutical II.

Values are means $\pm S E$; where $n=8$. In the same column; the similar superscript letters mean insignificant difference while the different superscript letters mean significant different at $P \leq 0.05$.

Prevention of both oxidative stress and inflammation could mitigate exposure to malignancy.

In the present study treatment with NDEA as procancerous agents increased biomarkers of inflammation and oxidative stress in plasma represented by elevation of TNF- $\alpha$ and MDA, respectively with reduction of enzymatic antioxidants exemplified by catalase denoting general condition of inflammation and oxidative stress in the whole body. Also, NDEA induced an elevated liver oxidative stress as indicated by increased liver MDA and reduced catalase associated with liver dysfunction as pointed from the elevated AST, ALT, ALP and reduced albumin. These changes might refer to the transition of liver to a pre-cancerous stage. MDA which is a product of lipid peroxidation might react with cell DNA producing MDA-DNA adduct inducing some sorts of mutation $(25,26)$ during genetic instability and emerged as a link between oxidative stress and cancer $(27,28)$. Genetic instability occurs due to sustained oxidative stress that leads to tumor progression. Elevated plasma ALT and AST which are indicators of liver damage were found to be correlated with tumor volume in hepatocellular carcinoma patient (29). Elevated ALP in NDEA control reflected hepatic lesions and tissue damage related to tumor formation that resulted in ALP release (30). NDEA is considered as hepatotoxin inducing inflammationassociated hepatocarcinogenesis. NDEA produced hepatocyte damage characterized by elevated serum alanine aminotransferase, TNF- $\alpha$, interleukin-6, myeloid cell infiltration and metastasis $(31,32)$. Inflammation and hepatocyte injury caused by chemical carcinogens induced high oxidative stress due to release of reactive oxygen species in liver which is a key factor in hepatocellular carcinoma progression (33). It is worthy to mention that the balance between reactive oxygen species and antioxidants assign the degree of oxidative stress. Inflammation and oxidative stress biomarkers (MDA) were elevated with simultaneous reduction of non- enzymatic and enzymatic antioxidant (including catalase) in hepatic tissue of mice treated by NDEA. Also, liver function indicators (ALT, AST, ALP and albumin) were reported to be elevated in NDEA treated rats and mice $(34,35)$. These results agreed with the present findings. NDEA treatment produced DNA damage, alteration in liver histopathology, increased fibrogenic marker (TGF- $\beta 1$ ) and regenerative proliferative stress (36). Also, a decrease in serum total protein was reported in NDEA treated animal (10) as could be seen in the current study.

The reduced final body weight together with the increase in percentage of liver weight/body weight in NDEA control might reflect the presence of some sorts of pathological condition related to malignancy with an increased liver weight that could be related to disturbance in nutrients metabolism, initiation of hyperplasia and/or tumor-genesis. Previously, NDEA was shown to induce decrease in body weight with increase in liver weight (36) which are similar to the present results.

The tested nutraceuticals in the current study showed protective effect through reducing oxidative stress and inflammation accompanied by elevated antioxidant level (catalase) in both plasma and liver. Treatment with the nutraceuticals improved liver function and body weight gain together with reducing percentage of liver weight/ body weight. NI was superior to NII in reversion of the pathological changes towards normal levels.

Green tea and broccoli in NI and NII are considered as source of phenolic compounds while wheat germ and hazel nuts as source of tocopherols and phytosterols. The presence of tomato and carrot in NI and NII, respectively are considered as source of carotenoids. Nutraceutical I and NII were reported to contain total phytosterols as $41.5 \%$ and $5.9 \%$ of total unsaponifiable matter, respectively represented by campesterol, stigmasterol and 
beta-sitosterol (14). It was demonstrated that sterols afford protection from cancer via an effect on immune function, an apoptotic effect and anti-inflammatory activity (37, 38). Hazel nuts and wheat germ oils are rich sources of tocopherols that reported to possess anticancer effect (39). NI was reported to contain $\alpha$-, $\gamma$ - and $\delta$-tocopherols as $266.29,98.44$ and 193.3 , respectively while they present as $54.7,0.73$ and $54.9 \mathrm{mg} / 100 \mathrm{~g}$ in NII. The anticancer effect of tocopherols could mainly belong to $\gamma$ - and $\delta$-tocopherols because they can scavenge reactive oxygen and nitrogen species in addition to their antiangiogenic effects and their ability to inhibit nuclear factor-kappa B pathway (39). Total phenolic compounds were present as 3.97 and $2.57 \mathrm{~g}$ gallic acid equivalent/100 $\mathrm{g}$ in NI and NII, respectively while $\beta$-carotene was 0.53 and 33.95 $\mathrm{mg} / 100 \mathrm{~g}$ (13). In the present study NI contained higher content of flavonoids compared to NII which could reflect the flavonoids content of green tea compared to broccoli while the flavonols of NII were higher than that of NI. It was reported that phenolic content of green tea comprised catechin, chrysin, syrngic, vanillic, cummaric, cinnamic, protocatechuic, sinapic and gallic acid (40). The major reported phenolic compounds in broccoli were two flavonol glycosides (quercetin 3-O-sophoroside and kaempferol 3-O- sophoroside) and four hydroxycinnamic acid esters (41). Phytochemicals in broccoli were demonstrated to possess anti-inflammatory and anticancer effects $(42,43)$. Bioactive compounds in green tea were reported to have anti-angiogenic, antimutagenic and anticancer effect $(44,45)$. Flavonoids present in broccoli and green tea have apoptotic activity and reduce proliferation in cancer cells $(46,47)$. Oxidative damage induced by chemical carcinogens was prevented by green tea polyphenol through inhibiting mitochondrial reactive oxygen species (48). Carotenoids in tomato and carrots have cancer protective effect (49). All the aforementioned bioactive constituents in the nutraceuticals might act synergistically to afford the antioxidant and anti-inflammatory activities and the improvement of liver function that could induce protective effect against liver cancer. The in-vitro antioxidant activities of NI and NII were demonstrated to be 64 and 74\%, respectively; in a previous study (14) which confirmed the in-vivo antioxidant effect in the present study.

The mechanism of anticancer protection might involve colon microbiota where significant increase in bifidobacteria on treatment with either NI or NII with simultaneous reduction in coliform and staphylococci on administration of NI were reported to correlate with the anti-inflammatory activity of nutraceuticals $(13,50)$. Inhibition of genotoxicity, prevention of oxidative DNA damage and minimization of DNA fragmentation and mutagenesis were demonstrated on administration of NI and NII (13) which might be among the anticancer mechanism of action of such nutraceuticals. The present study showed that the nutraceuticals may prevent cancer induced by NDEA at an early state of liver carcinogenesis in rats.

Although antioxidants could combat oxidative stress damage that induces carcinogenesis however they might also protect cancer cell from oxidative stress. Therefore, it might be claimed that antioxidants are protective from cancer incidence rather than curative agents. Nevertheless, antioxidant might serve as reducer of metastasis in cancer patients. Therefore, the balance between oxidative stress and antioxidants must be well investigated to prevent cancer progression and initiation.

\section{Conclusion}

Taken together the results of the present study demonstrated that the progression of hepatocarcinogenesis might be subsided by the tested nutraceuticals through antioxidant and anti-inflammatory actions.

\section{Acknowledgements}

The work was completely carried out in National Research Centre, Egypt.

\section{Authors' contributions}

ASY designed the study, wrote the manuscript with interpretation of the results. MDA and EHFH implemented the practical part. MDA wrote the first draft of the materials and methods. All authors read and approved the final version and agreed to publish it.

\section{Conflict of interests}

None to be declared

\section{Ethical considerations}

The animal experiment was confirmed by the Medical Research Ethics Committee, National Research Centre, Cairo, Egypt and followed the recommendations of the National Institute of Health Guide for Care and Use of Laboratory animals (Publication No-85-23, revised 1985).

\section{Funding/Support}

This research was not funded by any agency and was carried out on the expense of authors.

\section{References}

1. Alnajjar AM, Elsiesy HA. Natural products and hepatocellular carcinoma: a review. Hepatoma Res. 2015;1(3):119-24. doi: 10.4103/2394-5079.167379.

2. De Mey E, De Maere H, Paelinck H, Fraeye I. Volatile $\mathrm{N}$-nitrosamines in meat products: potential precursors, influence of processing, and mitigation strategies. Crit Rev Food Sci Nutr. 2017;57(13):2909-23. doi: 10.1080/10408398.2015.1078769.

3. Moreira AJ, Rodrigues G, Bona S, Cerski CT, Marroni CA, Mauriz JL, et al. Oxidative stress and cell damage in a model of precancerous lesions and advanced hepatocellular 
carcinoma in rats. Toxicol Rep. 2015;2:333-40. doi: 10.1016/j.toxrep.2014.11.015.

4. Verna L, Whysner J, Williams GM. N-nitrosodiethylamine mechanistic data and risk assessment: bioactivation, DNAadduct formation, mutagenicity, and tumor initiation. Pharmacol Ther. 1996;71(1-2):57-81. doi: 10.1016/01637258(96)00062-9.

5. Tricker AR, Ditrich C, Preussmann R. N-nitroso compounds in cigarette tobacco and their occurrence in mainstream tobacco smoke. Carcinogenesis. 1991;12(2):257-61. doi: 10.1093/carcin/12.2.257.

6. Ferlay J, Shin HR, Bray F, Forman D, Mathers C, Parkin DM. Estimates of worldwide burden of cancer in 2008: GLOBOCAN 2008. Int J Cancer. 2010;127(12):2893-917. doi: $10.1002 /$ ijc. 25516.

7. Sartorius K, Sartorius B, Aldous C, Govender PS, Madiba TE. Global and country underestimation of hepatocellular carcinoma (HCC) in 2012 and its implications. Cancer Epidemiol. 2015;39(3):284-90. doi: 10.1016/j. canep.2015.04.006.

8. Erkekoglu P, Oral D, Chao MW, Kocer-Gumusel B. Hepatocellular carcinoma and possible chemical and biological causes: a review. J Environ Pathol Toxicol Oncol. 2017;36(2):171-90. doi: 10.1615/ JEnviron PatholToxicolOncol.2017020927.

9. Kangari P, Zarnoosheh Farahany T, Golchin A, Ebadollahzadeh S, Salmaninejad A, Mahboob SA, et al. Enzymatic antioxidant and lipid peroxidation evaluation in the newly diagnosed breast cancer patients in Iran. Asian Pac J Cancer Prev. 2018;19(12):3511-5. doi: 10.31557/ apjcp.2018.19.12.3511.

10. Zayed Mohamed N, Aly HF, Moneim El-Mezayen HA, ElSalamony HE. Effect of co-administration of Bee honey and some chemotherapeutic drugs on dissemination of hepatocellular carcinoma in rats. Toxicol Rep. 2019;6:87588. doi: $10.1016 /$ j.toxrep.2019.08.007.

11. Wang $\mathrm{T}$, Johnson LA. Refining high-free fatty acid wheat germ oil. J Am Oil Chem Soc. 2001;78(1):71-6. doi: 10.1007/ s11746-001-0222-2.

12. Fuhrman B, Elis A, Aviram M. Hypocholesterolemic effect of lycopene and beta-carotene is related to suppression of cholesterol synthesis and augmentation of LDL receptor activity in macrophages. Biochem Biophys Res Commun. 1997;233(3):658-62. doi: 10.1006/bbrc.1997.6520.

13. Al-Okbi SY, Mohamed DA, Donya SM, Abd El Khalek AB. Role of Bifidobacterium bifidum and plant food extracts in improving microflora and biochemical and cytogenetic parameters in adjuvant arthritis. Grasas y Aceites. 2011;62(3):308-20. doi: 10.3989/gya.089810.

14. Al-Okbi SY, Mohamed DA. Evaluation of the anticancer effect of nutraceuticals. Adv Food Sci. 2011;33(4):230-6.

15. Ordoñez AAL, Gomez JD, Vattuone MA, lsla MI. Antioxidant activities of Sechium edule (Jacq.) Swartz extracts. Food Chem. 2006;97(3):452-8. doi: 10.1016/j. foodchem.2005.05.024.

16. Kumaran A, Joel Karunakaran R. In vitro antioxidant activities of methanol extracts of five Phyllanthus species from India. LWT Food Sci Technol. 2007;40(2):344-52. doi: 10.1016/j.lwt.2005.09.011.

17. Srivastava S, Singh M, Roy P, Prasad S, George J, Shukla Y.
Inhibitory effect of tea polyphenols on hepatic preneoplastic foci in Wistar rats. Invest New Drugs. 2009;27(6):526-33. doi: 10.1007/s10637-008-9204-6.

18. Reitman S, Frankel S. A colorimetric method for the determination of serum glutamic oxalacetic and glutamic pyruvic transaminases. Am J Clin Pathol. 1957;28(1):56-63. doi: 10.1093/ajcp/28.1.56.

19. Babson AL, Greeley SJ, Coleman CM, Phillips GE. Phenolphthalein monophosphate as a substrate for serum alkaline phosphatase. Clin Chem. 1966;12(8):482-90.

20. Rheinhold JG. Total protein, albumin and globulin in standard methods of clinical chemistry. D. Seligron, Ed. Vol. I. New York: Academic press, Inc; 1953. p. 88.

21. Doumas BT, Watson WA, Biggs HG. Albumin standards and the measurement of serum albumin with bromcresol green. Clin Chim Acta. 1971;31(1):87-96. doi: 10.1016/00098981(71)90365-2.

22. Satoh K. Serum lipid peroxide in cerebrovascular disorders determined by a new colorimetric method. Clin Chim Acta. 1978;90(1):37-43. doi: 10.1016/0009-8981(78)90081-5.

23. Aebi H. Catalase in vitro. Methods Enzymol. 1984;105:1216. doi: 10.1016/s0076-6879(84)05016-3.

24. Stepaniak JA, Gould KE, Sun D, Swanborg RH. A comparative study of experimental autoimmune encephalomyelitis in Lewis and DA rats. J Immunol. $1995 ; 155(5): 2762-9$.

25. Munnia A, Bonassi S, Verna A, Quaglia R, Pelucco $\mathrm{D}$, Ceppi $\mathrm{M}$, et al. Bronchial malondialdehyde DNA adducts, tobacco smoking, and lung cancer. Free Radic Biol Med. 2006;41(9):1499-505. doi: 10.1016/j. freeradbiomed.2006.08.007.

26. Ramakrishnan G, Augustine TA, Jagan S, Vinodhkumar $\mathrm{R}$, Devaki T. Effect of silymarin on N-nitrosodiethylamine induced hepatocarcinogenesis in rats. Exp Oncol. 2007;29(1):39-44.

27. Zienolddiny S, Ryberg D, Haugen A. Induction of microsatellite mutations by oxidative agents in human lung cancer cell lines. Carcinogenesis. 2000;21(8):1521-6.

28. Valko M, Izakovic M, Mazur M, Rhodes CJ, Telser J. Role of oxygen radicals in DNA damage and cancer incidence. Mol Cell Biochem. 2004;266(1-2):37-56. doi: 10.1023/b:mc bi.0000049134.69131.89.

29. Rocchi E, Seium Y, Camellini L, Casalgrandi G, Borghi A, D'Alimonte P, et al. Hepatic tocopherol content in primary hepatocellular carcinoma and liver metastases. Hepatology. 1997;26(1):67-72. doi: 10.1053/jhep.1997.v26. pm0009214453.

30. Iqbal J, Minhajuddin M, Beg ZH. Suppression of diethylnitrosamine and 2-acetylaminofluorene-induced hepatocarcinogenesis in rats by tocotrienol-rich fraction isolated from rice bran oil. Eur J Cancer Prev. 2004;13(6):515-20. doi: 10.1097/00008469-20041200000009.

31. Liu Y, Zhang J, Liu H, Guan G, Zhang T, Wang L, et al. Compensatory upregulation of aldo-keto reductase $1 \mathrm{~B} 10$ to protect hepatocytes against oxidative stress during hepatocarcinogenesis. Am J Cancer Res. 2019;9(12):273048.

32. Owumi SE, Aliyu-Banjo NO, Danso OF. Fluoride and diethylnitrosamine coexposure enhances oxido- 
inflammatory responses and caspase-3 activation in liver and kidney of adult rats. J Biochem Mol Toxicol. 2019;33(7):e22327. doi: 10.1002/jbt.22327.

33. Ivanov AV, Valuev-Elliston VT, Tyurina DA, Ivanova ON, Kochetkov SN, Bartosch B, et al. Oxidative stress, a trigger of hepatitis C and B virus-induced liver carcinogenesis. Oncotarget. 2017;8(3):3895-932. doi: 10.18632/ oncotarget.13904.

34. Ahmed OM, Ahmed AA, Fahim HI, Zaky MY. Quercetin and naringenin abate diethylnitrosamine/ acetylaminofluorene-induced hepatocarcinogenesis in Wistar rats: the roles of oxidative stress, inflammation and cell apoptosis. Drug Chem Toxicol. 2019:1-12. doi: 10.1080/01480545.2019.1683187.

35. Adebayo OA, Akinloye O, Adaramoye OA. Cerium oxide nanoparticles attenuate oxidative stress and inflammation in the liver of diethylnitrosamine-treated mice. Biol Trace Elem Res. 2020;193(1):214-25. doi: 10.1007/s12011-01901696-5.

36. Dwivedi DK, Jena GB. Diethylnitrosamine and thioacetamide-induced hepatic damage and early carcinogenesis in rats: Role of Nrf2 activator dimethyl fumarate and NLRP3 inhibitor glibenclamide. Biochem Biophys Res Commun. 2020;522(2):381-7. doi: 10.1016/j. bbrc.2019.11.100.

37. Awad AB, Fink CS. Phytosterols as anticancer dietary components: evidence and mechanism of action. J Nutr. 2000;130(9):2127-30. doi: 10.1093/jn/130.9.2127.

38. de Jong A, Plat J, Mensink RP. Metabolic effects of plant sterols and stanols (Review). J Nutr Biochem. 2003;14(7):362-9. doi: 10.1016/s0955-2863(03)00002-0.

39. Abraham A, Kattoor AJ, Saldeen T, Mehta JL. Vitamin $\mathrm{E}$ and its anticancer effects. Crit Rev Food Sci Nutr. 2019;59(17):2831-8. doi: 10.1080/10408398.2018.1474169.

40. Al-Okbi SY, Mohamed DA, Hamed TE, Mohamed MS, El-Sayed EM, Mabrok HB. Prevention of hepatorenal syndrome by green tea, branched chain amino acids and mannitol in rat model. Res J Pharm Biol Chem Sci. 2016;7(3):1852-64.
41. Plumb GW, Price KR, Rhodes MJ, Williamson G. Antioxidant properties of the major polyphenolic compounds in broccoli. Free Radic Res. 1997;27(4):429-35. doi: $\quad 10.3109 / 10715769709065782$.

42. Brown KK, Blaikie FH, Smith RA, Tyndall JD, Lue $\mathrm{H}$, Bernhagen J, et al. Direct modification of the proinflammatory cytokine macrophage migration inhibitory factor by dietary isothiocyanates. J Biol Chem. 2009;284(47):32425-33. doi: 10.1074/jbc.M109.047092.

43. Fowke JH, Chung FL, Jin F, Qi D, Cai Q, Conaway C, et al. Urinary isothiocyanate levels, brassica, and human breast cancer. Cancer Res. 2003;63(14):3980-6.

44. Pfeffer U, Ferrari N, Morini M, Benelli R, Noonan DM, Albini A. Antiangiogenic activity of chemopreventive drugs. Int J Biol Markers. 2003;18(1):70-4. doi: 10.5301/ jbm.2008.5042.

45. Yang CS, Maliakal P, Meng X. Inhibition of carcinogenesis by tea. Annu Rev Pharmacol Toxicol. 2002;42:25-54. doi: 10.1146/annurev.pharmtox.42.082101.154309.

46. Mu LN, Zhou XF, Ding BG, Wang RH, Zhang ZF, Chen $\mathrm{CW}$, et al. [A case-control study on drinking green tea and decreasing risk of cancers in the alimentary canal among cigarette smokers and alcohol drinkers]. Zhonghua Liu Xing Bing Xue Za Zhi. 2003;24(3):192-5.

47. Chen D, Chen MS, Cui QC, Yang H, Dou QP. Structureproteasome-inhibitory activity relationships of dietary flavonoids in human cancer cells. Front Biosci. 2007;12:1935-45. doi: 10.2741/2199.

48. Lambert JD, Yang CS. Mechanisms of cancer prevention by tea constituents. J Nutr. 2003;133(10):3262S-7S. doi: $10.1093 / \mathrm{jn} / 133.10 .3262 \mathrm{~S}$.

49. Heber D. Colorful cancer prevention: $\alpha$-carotene, lycopene, and lung cancer. Am J Clin Nutr. 2000;72(4):901-2. doi: 10.1093/ajcn/72.4.901.

50. Al-Okbi SY. Nutraceuticals of anti-inflammatory activity as complementary therapy for rheumatoid arthritis. Toxicol Ind Health. 2014;30(8):738-49. doi: $10.1177 / 0748233712462468$. 